\title{
Bokrecension: Strengthening Teaching and Learning in Research Universities. Strategies and Initiatives for Institutional Change
}

Bjørn Stensaker, Graham T. Bilbow, Lori Breslow \& Rob van der Vaart (Eds.). Strengthening Teaching and Learning in Research Universities. Strategies and Initiatives for Institutional Change. Palgrave Macmillan, 20I7, $228 \mathrm{p}$.

\section{INLEDNING}

För några veckor sedan mötte jag en nyanställd kollega som hade haft en anställning vid en mindre högskola och som nu arbetade vid Uppsala universitet. Vi diskuterade likheter och olikheter mellan arbetsplatserna och han reflekterade över hur annorlunda, trögt och "tungrott" förändringar av utbildning framstod vid det stora, forskningstunga universitetet i jämförelse med den mindre högskolan. I boken Strengthening Teaching and Learning in Research Universities. Strategies and Initiatives for Institutional Change (Ed. Bjørn Stensaker, Grahame T. Bilbow, Lori Breslow and Rob van der Vaart) diskuteras initierat några av de utmaningar man möter då man vill höja undervisningens betydelse vid forskningstunga universitet. Författarna är verksamma vid olika forskningstunga universitet ingående i Network for the Enhancement of Teaching and Learning som initierades av Graham Gibbs 2004.

Jag kan varmt rekommendera boken för dig som är intresserad av utmaningar i den högre utbildningen. Den är skriven av erfarna pedagogiska ledare och experter och tack vare det får läsaren kompetenta beskrivningar och analyser samt goda referenser till högskolepedagogisk litteratur. Den är också läsvärd för dig som är specialintresserad av universitetens organisation och struktur och stödet för högre utbildning samt, naturligtvis, för dig som är allmänt intresserad av högskolepedagogik och de principer och normer som ligger till grund för högre utbildning.

Boken är delvis en hyllning till Graham Gibbs, en framträdande forskare och praktiker inom högskolepedagogiken. Han har skrivit en avslutande reflektion över bokens kapitel och han är som vanligt knivskarp i sin analys. Han beskriver med följande skämt från Oxford hur svårt det kan vara att åstadkomma förändringar vid forskningstunga universitet: How many academics does it take to change a light bulb? The answer was "Change?" Läs hans kapitel först!

BOKENS SYFTE

I bokens förord beskrivs ett av syftena med boken:

"..., define teaching as an intellectual activity, and help our institutions reach a standard of excellence in teaching and learning on par with their reputation in research." (Breslow et al., Foreword, vii)

Universiteten har under större delen av 1900-talet fokuserat på forskningen. Effekten har blivit en uppdelning mellan forskning, undervisning och förvaltning vid universiteten. Denna har

*Författarkontakt: Svante.Axelsson@uadm.uu.se

Artiklar och reflektioner är kollegialt granskade. Övriga bidragstyper granskas av redaktionen. Se www.hogreutbildning.se ISSN 2000-7558

(C) 2018 Svante Axelsson. This is an Open Access article distributed under the terms of the Creative Commons Attribution-NonCommercial 4.0 International License (https://creativecommons.org/licenses/by-nc/4.0/), allowing third parties to share their work (copy, distribute, transmit) and to adapt it, under the condition that the authors are given credit, that the work is not used for commercial purposes, and that in the event of reuse or distribution, the terms of this license are made clear.

Citation: Svante Axelsson (2018) «Bokrecension: Strengthening Teaching and Learning in Research Universities. Strategies and Initiatives for Institutional Change», Högre utbildning, 8(2), 51-54. http://dx.doi.org/10.23865/hu.v8.1253 
lett till en splittring av den akademiska identiteten i olika roller som forskaren, läraren och administratören. Ett underliggande antagande har varit att om undervisningen sköts av duktiga forskare, speciellt om man har rekryterat duktiga studenter som många av de i boken medverkande universiteten har, så blir undervisningen bra. Detta samband har dock gång efter annan motbevisats. Två huvudfrågor behandlas i boken: Hur kan forskningstunga universitet stödja utveckling av undervisning? och Blir stödet effektivt?

\section{BOKENS KAPITEL}

Första kapitlet av Björn Stensaker et al. öppnar dörren till ett antal av de utmaningar som universiteten brottas med då de vill stärka undervisningen. Bokens övriga kapitel fördjupar resonemangen kring olika utmaningar. Efter inledning och analys av en utmaning ges exempel på hur några universitet har valt att arbeta med utmaningen samt vilka konsekvenser det har fått. Kapitlen beskriver i tur och ordning: strukturering och organisation av akademisk utveckling; exempel på ämnesdidaktiska angreppssätt och hur man ser på de två rollerna pedagogiska experter och ämnesexperter; utveckling av pedagogiskt ledarskap; pedagogisk fortbildning för lärare; akademier för universitetets befordrade eller excellenta lärare; pedagogiska samtals- och diskussionsfora samt exempel på hur två universitet har jobbat för att studera effekten av pedagogiska insatser.

\section{VALDA DELAR UR INNEHÅLLET}

En viktig fråga inom högskolepedagogiken är vad som påverkar undervisningen inom ett ämne; om det är institutionens eller utbildningsprogrammets undervisningskultur och tradition eller om det är pedagogik och metoder inom ämnesdidaktiken som sätter sin prägel. I kapitlet $E d u-$ cation Enhancement in the Disciplines ges exempel på hur resurser har gått till utveckling av ämnesdidaktik istället för till universitetsövergripande pedagogik. En av anledningarna och argumenten för detta är, enligt författarna, att det är lättare för forskningsförankrade lärare som har stora ämneskunskaper att utveckla en didaktisk förståelse i det egna ämnet än att delta i fortbildning som beskriver universitetspedagogik i mer allmänpedagogiska termer och principer. I kapitlet beskrivs hur tre universitet (Oxford, Köpenhamn och Leuven) arbetat med utveckling av ämnesdidaktiken. Utvecklingsprojekten har fokuserat på pedagogisk utveckling för lärarpersonal som ingår i starkt ämnesbundna forskningsmiljöer och utgångspunkten har varit att det finns stora olikheter mellan ämneskulturer vid ett stort universitet, i både innehåll, modeller och metoder. Beskrivningarna och de referenser som författarna hänvisar till är mycket läsvärda.

I kapitlet Faculty Development for Educational Leadership där bl.a. Katarina Mårtensson, Lunds universitet, är medförfattare beskrivs utvecklingen av pedagogiskt ledarskap vid fem olika universitet. Kapitlet visar hur viktig pedagogiska ledares förståelse för kvalitativa aspekter är på kunskap, ämnesdidaktisk undervisning och resurser i form av både personal, utrustning och till exempel servicefunktioner för att kunna leda utbildningen på ett effektivt sätt.

Åsa Lindberg-Sand och Maria Larsson, Lunds universitet, medverkar i ett kapitel där de beskriver arbetet med att utveckla pedagogiska akademier, något som startades vid Lunds tek-niska högskola för cirka I5 år sedan. ${ }^{.}$Arbetet har utgått från en modell där ett kollegialt nät-verk arbetar för att uppmärksamma och synliggöra lärarskicklighet. Många av de lärosäten som

1 Vid många svenska lärosäten finns nu olika arbetssätt och pedagogiska meriteringsmodeller. Katarina Winka vid Umeå universitet har kartlagt och beskrivit dessa i en rapport som finns publicerad vid Göteborgs universitet (Katarina Winka, PIL-rapport 2017:02). 
nämns i boken har använt sig av speciella pedagogiska, akademiska sällskap som arbetar för att skapa karriärvägar, miljöer och fora för excellenta lärare. Arbetet grundar sig på idén om att skapa liknande karriärförutsättningar för lärare som satsar på undervisning och utbildning, som det finns karriärvägar inom forskningen.

I kapitlet Fostering dialogue about practice av Bilbow et al. refererar författarna, som flera andra författare i boken, till Graham Gibbs artikel från 20I3 där han analyserar ett antal strategier för att utveckla undervisningen inom högre utbildning. Strategierna baseras på elva olika typer av aktiviteter. Han beskriver hur utveckling av högskolepedagogiken kräver beslut och engagemang på olika nivåer inom universitetet, i olika organisatoriska och politiska sammanhang. En viss del av verksamheten kan genomföras av den enskilde läraren medan andra kräver beslut på högre nivåer. Fungerande insatser för utvecklingen är t.ex. universitetspedagogiska kurser för lärare, utbildning för lärarlag eller institutioner, kvalitetsutvärderingar och universitetsgemensamma satsningar samt nya rutiner och regler.

I Bilbows kapitel används en modell av Trowler et al. (2005) som visar hur man genom att fokusera på tre olika nivåer kan nå utveckling och förbättring; på en mikronivå (enskilda lärare), en makronivå (universitetet) och en mesonivå (undervisningen med dess involverade studenter och lärare). Författarna refererar bland annat till forskning av Mårtensson, Roxå och Stensaker (20I4) som beskriver välfungerande mikrokulturer som enheter av lärare, t.ex. ett lärarlag eller en avdelning som planerar, genomför och utvecklar undervisning tillsammans. En viktig aspekt för att kunna utveckla undervisningens kvalitet är att låta dessa mikrokulturer få mer kontroll över kvalitetsutvärderingarna.

\section{EVIDENSBASERAD UNDERVISNING}

I det näst sista kapitlet utgår Lindblom-Ylänne och Breslow från att lärare och forskare inom många discipliner vid universitetet efterfrågar evidens inte bara för forskningsresultat utan även i jämförelse mellan olika undervisningsformer.

"Finns det inga evidens? Nähä, då ändrar jag inget och fortsätter som jag alltid har gjort." (citat från universitetslärare)

Författarna menar att universiteten måste argumentera för sina strävanden att utveckla undervisningen och stödja studenternas lärande med hjälp av evidensbaserade resultat. Det förutsätter att man tar tillvara forskning inte bara från pedagogik utan också från flera andra fält som t.ex. psykologi och ämnesdidaktik. Forskningen kan användas både för att stödja lärares "beprövade erfarenhet" och för att visa på komplexa och kanske negativa samband. Kapitlet beskriver två projekt från Helsingfors universitet där Lindblom-Ylänne och hennes kollegor har studerat veterinärstudenters upplevelser av studier som stressande och ojämnt fördelade. Efter en översyn och omfördelning av poäng och arbetsbelastning mellan kurser uppnåddes en positiv förändring för studenterna som upplevde att arbetsbelastningen blivit mer jämnt fördelad.

I det andra projektet utvärderades studenters kunskapsprestationer i förhållande till vilka utmaningar de upplevde under kurserna. Resultaten visade att för låga eller för höga utmaningar ställer till med problem för många studenter.

Boken kan läsas som den antologi den är: välj det kapitel som är mest intressant för dig och din verksamhet. Varje kapitel innehåller många bra referenser som gör att du får chans att ytterligare förkovra dig inom området. De ibland lite omfattande bakgrundsbeskrivningarna 


\section{Svante Axelsson}

av universiteten har inte alltid intresserat mig men i övrigt så framstår innehållet som mycket användbart för lärare, chefer och rektorer vid alla landets universitet. God läsning!

Svante Axelsson

Pedagogisk utvecklare Enheten för universitetspedagogik

Uppsala universitet Svante.Axelsson@uadm.uu.se

\section{REFERENSER}

Gibbs, G. (2013). Reflections on the changing nature of educational development. International Journal of Academic Development, 18, 4-14.

Mårtensson, K., Roxå, T., \& Stensaker, B. (2014). From quality assurance to quality practices: An investigation of strong microcultures in teaching and learning. Studies in Higher Education, 39, 534-545.

Trigwell, T., Prosser, M., \& Waterhouse, F. (1999). Relations between teacher's approaches to teaching and students' approaches to learning. Higher Education, 37, 57-70.

Trowler, P., Fanghanel, J., \& Wareham, T. (2005). Freeing the chi of change: The Higher education Academy and enhancing teaching and learning in higher education. Studies in Higher education, 30, 427-444.

Winka, K. (2017). PIL-rapport 2017:02 (Göteborgs universitet). 